\title{
Oscillatory reactions in the acetone-glucose-sodium bromate-sulfuric acid system with a tetraazamacrocyclic copper (II) complex as a catalyst
}

\author{
Lin $\mathrm{Hu}^{*}$, BinBin Li, SanChun Wei,YeGui Wang, MiWei Hu,WenYuan Xu \\ Institute of Applied Chemistry, East China Jiaotong University, 330013,Nanchang , P.R. China
}

\begin{abstract}
The behavior of glycolysis concerning the biochemical reaction was thought to be similar to the oscillatory reaction with glucose being the substrate. The objective of this research is to find a new oscillatory system and study its relevant properties, so new $\mathrm{Cu}$ (II)-catalyzed oscillating reaction involved glucose and acetone as the double substrates was investigated systematically. As a function of reaction temperature and concentration of glucose, bromate, and acetone, the features in this novel oscillation system was studied. The results showed that the activation energy reached up to $90.839 \mathrm{KJ} / \mathrm{mol}$ and the oxidized product of the double substrates provided the impetus in the course of the new oscillating reaction. A tentative mechanism was considered on the basis of FNK.
\end{abstract}

\section{Introduction}

Nature is the best teacher showing us how to effective use energy. Most creatures on the Earth, including animal, plant as well as yeast has shown an example of successful pathway taking energy from glycolysis[1]. Glycolysis that is the ultimate source of energy keeping creatures survive is the metabolic pathway that converts glucose into pyruvate and releases free energy to form the high-energy compounds ATP and $\mathrm{NADH}$.It was first found that glycolysis is a determined sequence of ten enzyme-catalyzed complex reactions resulting in oscillation of $\mathrm{NADH}$ concentration in yeast in 1968[2].

The Belousov-Zhabotinskii oscillating reaction was found long ago and studied thoroughly. The classical BZ oscillatory systems consist of malonic acid, $\mathrm{Ce}(\mathrm{IV}) / \mathrm{Ce}(\mathrm{III})$ or $\mathrm{Mn}(\mathrm{III}) / \mathrm{Mn}(\mathrm{II})$ redox catalyst and $\mathrm{KBrO}_{3}$ in solutions of $\mathrm{H}_{2} \mathrm{SO}_{4}[3]$. With regard to the Corresponding author:hulin21@ hotmail.com catalyst in the BZ oscillatory systems, many researchers paid much attention to metallic ion in the past and further research on $\mathrm{Ce}(\mathrm{IV}) / \mathrm{Ce}(\mathrm{III})$ [4-9]. In 1982, the tetraazamacrocyclic complexes of $\mathrm{Cu}$ ( II ) and $\mathrm{Ni}$ ( II ) were first found to act as a catalyst for BZ oscillating reactions. The design and synthesis of macrocycles and their metal complexes attract great attention, resulting from their widespread applications in biology, chemistry and in other applications of science[10]. The features of the oscillating reactions catalyzed by tetraazamacrocyclic complex differ from the classical oscillating reaction in accordance with relevant literature[11-14].The tetraazamacrocyclic complex and organic substrate play a crucial role in the new oscillation reaction because the tetrazamacrocyclic complex is similar to some enzymes, so the newly oscillating reaction is deemed 
to be a man-made biochemical scillation. It is significant to study the chemical oscillation on the basis of glucose as the analogy to glycolysis.

In this research, we have investigated the behavior of glucose and acetone, two important substrates in normal metabolism. As a result, new oscillating reactions in the g-acetone-glucose-sodium bromatesulfuric acid system using tetraazamacrocyclic copper( II ) complex $[\mathrm{Cu} \mathrm{L}]\left(\mathrm{ClO}_{4}\right)_{2}$ as catalyst are reported. The ligand $\mathrm{L}$ in the complex is $5,7,7,12,, 14,14$ -hexamethyl-1,4,8,11tetraazacyclotetradeca-4,11-dine.

\section{Experiment}

In accordance with the relevant dissertation[15-17],

$\left[\begin{array}{ll}\mathrm{Cu} & \mathrm{L}\end{array}\right]\left(\mathrm{ClO}_{4}\right)_{2}$ was prepared, whose structure is measured by IR . [Cu L] $\left(\mathrm{ClO}_{4}\right)_{2}$ is used as the catalyst in this chemical oscillatory system. The water used in the experiment is twice redistilled to ensure the removal of impurities. The reagents prepared in this system were of analytical grade. The most important thing is that the $\mathrm{NaBrO}_{3}$ needs to be recrystallized from hot water twice to move $\mathrm{Br}^{-}$and other impurities. This chemical oscillatory experiment was conducted in a closed glass container at $30^{\circ} \mathrm{C}$ under constant stirring. A constant $\mathrm{N}_{2}$ flow of $400 \mathrm{ml} / \mathrm{min}$ in $40 \mathrm{ml}$ reaction solution was maintained by a capillary flow indicator. The redox potential of the reacting system was measured with a smooth platinum electrode vs. a $\mathrm{Hg}\left(\mathrm{Hg}_{2} \mathrm{Cl}_{2}\right) \mathrm{K}_{2} \mathrm{SO}_{4}$ reference electrode, and the bromide ions concentration was measured with a bromide selective electrode, then all results were collected on a y-t recorder.

We carried out more than 50 experiments, and the explored ranges of the initial major reactant concentrations are reported in table 1, except for sulfate acid at a fixed temperature. According to the above general regularity, the different behavior of the oscillation in which the major reactant concentration are kept at different temperatures is studied. Typical potentiometric oscillation traces of platinum electrode and bromide selective electrode are shown in Fig.7.

During the oscillations, the solution color changed periodically between orange and faint yellow, indicating the oscillation between $[\mathrm{Cu} \mathrm{L}]^{2+}$ and $[\mathrm{Cu}$ $\mathrm{L}^{3+}$. At the same time, the relationship between the potential of the platinum electrode and the potential of the bromide ion electrode is also studied in detail, through their potential respectively.

Table 1 the ranges of initial major reactant concentrations in the system

\begin{tabular}{llll}
\hline $\begin{array}{l}\mathrm{NaBrO}_{3} \\
(\mathrm{~mol} / \mathrm{L})\end{array}$ & $\begin{array}{l}\text { Glucose } \\
(\mathrm{mol} / \mathrm{L})\end{array}$ & $\begin{array}{l}\text { Acetone } \\
(\mathrm{mol} / \mathrm{L})\end{array}$ & $\begin{array}{l}{[\mathrm{Cu} \mathrm{L}]\left(\mathrm{ClO}_{4}\right)_{2}} \\
(\mathrm{~mol} / \mathrm{L})\end{array}$ \\
\hline $0.04-0.20$ & 0.06 & 0.65 & 0.05 \\
\hline 0.08 & $0-0.06$ & 0.65 & 0.05 \\
\hline 0.08 & 0.06 & $0.25-2.05$ & 0.05 \\
\hline 0.08 & 0.06 & 0.65 & $0.01-0.21$ \\
\hline
\end{tabular}

\section{Result and discussions}

As a result, this newly oscillatory system catalyzed by $[\mathrm{Cu} \mathrm{L}]\left(\mathrm{ClO}_{4}\right)_{2}$ displayed classical obvious oscillatory feature. The mean values of the following oscillatory parameters were calculated: oscillatory $\operatorname{period}\left(\mathrm{t}_{\mathrm{p}}\right)$, oscillatory cycles(n) and oscillatory amplitude (A). The characteristics of oscillations is based on the concentration of bromate ions, glucose, acetone and $[\mathrm{Cu} \mathrm{L}]\left(\mathrm{ClO}_{4}\right)_{2}$. The effects of the double substrate on oscillation parameter is shown in Fig.1.

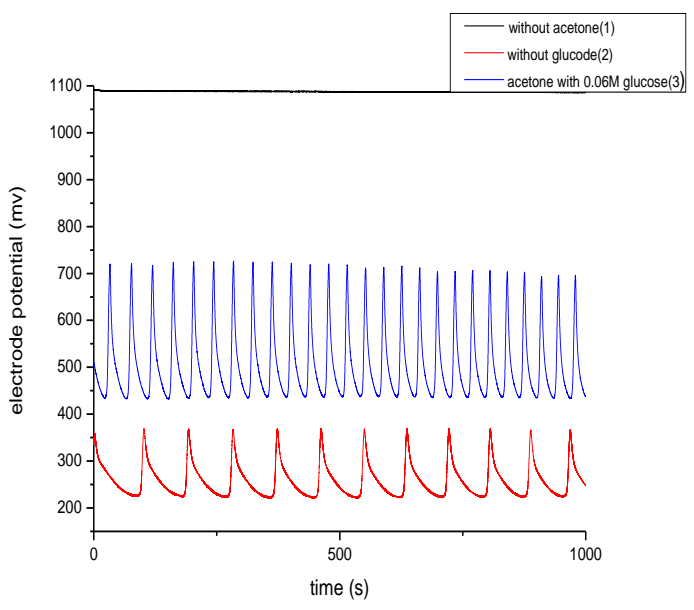

Fig.1. the effects of substrate on the oscillation 
As shown from Fig.1, the three conclusion can be made: Firstly,the oscillation can not exist without acetone in the whole oscillatory system. Secondly, when glucose is not added to the system,the oscillatory reaction still happen. Thirdly, the double substrate can make the oscillatory amplitude bigger and the oscillatory period shorter than without glucose.

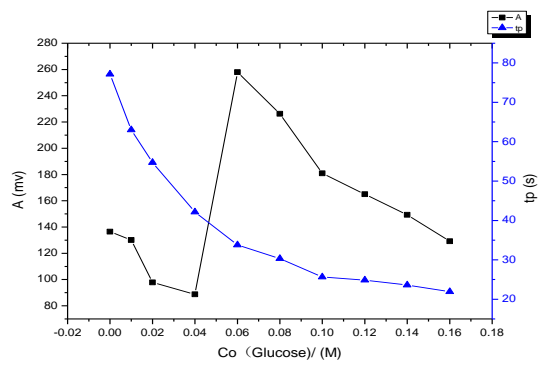

Fig.2. The effects of [Glucose $]_{0}$ on the oscillation period (tp),the amplitude of oscillation (A) at $30^{\circ} \mathrm{C}$ :

$$
\begin{aligned}
& {[\text { Acetone }]_{0}=0.65 \mathrm{M},\left[\mathrm{H}_{2} \mathrm{SO}_{4}\right]_{0}=1.05 \mathrm{M}} \\
& {\left[\mathrm{CuL}^{2+}\right]_{0}=0.05 \mathrm{M},\left[\mathrm{NaBrO}_{3}\right]_{0}=0.08 \mathrm{M}}
\end{aligned}
$$

As shown from the figure.2, oscillation still takes place without the glucose. The amplitude of oscillation decreased with increasing glucose concentration and reached a minimum at $[\text { glucose }]_{0}$ ca. $0.04 \mathrm{M}$, then rose with further increasing the glucose concentration until the glucose concentration was $0.06 \mathrm{M}$, finally decreased as the glucose concentration increased. The oscillation period (tp) became increasingly shorter with increasing glucose concentration throughout the experiment.

The effect of the concentration of acetone on oscillation parameter is shown in Fig.3. When the concentration of acetone was $0.85 \mathrm{M}$, the oscillatory amplitude achieves the maximum.when the concentration of acetone increased to $1.05 \mathrm{M}$,the oscillatory period is the longest.The effect of the concentration of $\mathrm{CuL}^{2+}$ and $\mathrm{NaBrO}_{3}$ oscillation parameter are shown in Fig.4 and Fig.5,respectively. Like the effect of acetone, the trend for the curve of the effect of $\mathrm{CuL}^{2+}$ and $\mathrm{NaBrO}_{3}$ on the oscillation parameter is similar.With the increasing concentration of reactant in the oscillatory system, no matter the amplitude or period initially, they are boosted and then subsequently lowered.

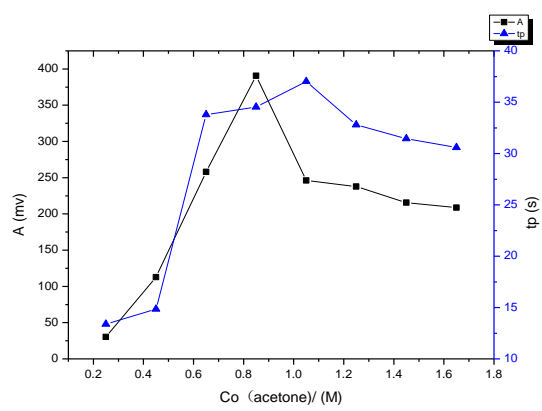

Fig.3. The effects of [Acetone]0 on the oscillation period (tp), the amplitude of oscillation (A) at $30^{\circ} \mathrm{C}$ : [Glucose $] 0=0.06 \mathrm{M},\left[\mathrm{H}_{2} \mathrm{SO}_{4}\right] 0=1.05 \mathrm{M}$,

$\left[\mathrm{CuL}^{2+}\right] 0=0.05 \mathrm{M}, \quad\left[\mathrm{NaBrO}_{3}\right] 0=0.08 \mathrm{M}$

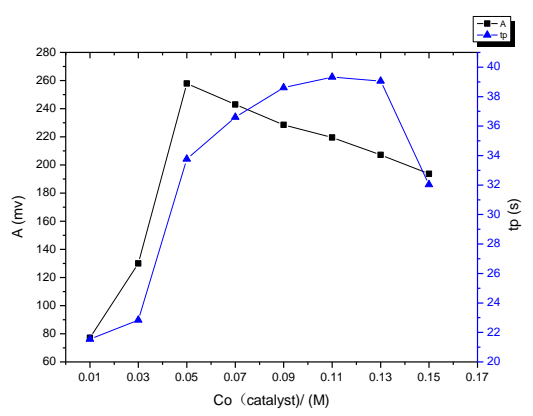

Fig.4. The effects of $\left[\mathrm{CuL}^{2+}\right]_{0}$ on the oscillation period (tp), the amplitude of oscillation (A) at $30^{\circ} \mathrm{C}$ :

$[\text { Glucose }]_{0}=0.06 \mathrm{M},\left[\mathrm{H}_{2} \mathrm{SO}_{4}\right]_{0}=1.05 \mathrm{M}$

$[\text { Acetone }]_{0}=0.65 \mathrm{M},\left[\mathrm{NaBrO}_{3}\right]_{0}=0.08 \mathrm{M}$

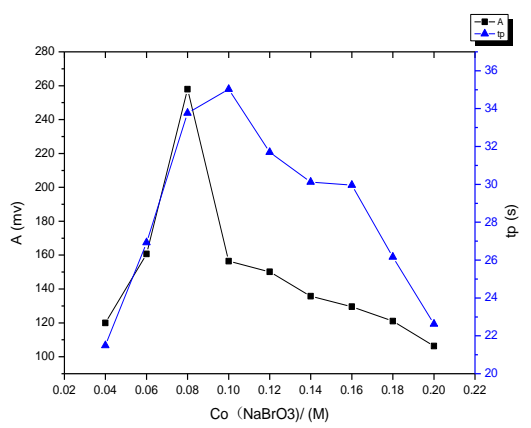

Fig.5. The effects of $\left[\mathrm{NaBrO}_{3}\right]_{0}$ on the oscillation Period $\left(\mathrm{t}_{\mathrm{p}}\right)$, the amplitude of oscillation of oscillation(A) at $30^{\circ} \mathrm{C}$ :

$[\text { Glucose }]_{0}=0.06 \mathrm{M},\left[\mathrm{H}_{2} \mathrm{SO}_{4}\right]_{0}=1.05 \mathrm{M}$

$[\text { Acetone }]_{0}=0.65 \mathrm{M},\left[\mathrm{CuL}^{2+}\right]_{0}=0.05 \mathrm{M}$ 
The reaction was also studied at different temperature , and the oscillation period (tp) was found to be inversely related to temperature. As the temperature increased, the oscillation period (tp) decreased. From the Arrhenius plot (Fig.6) of $1 \mathrm{n}\left(1 / \mathrm{t}_{\mathrm{p}}\right)$ v s $1 / \mathrm{T}$, the activation energy was calculated as 90.839 $\mathrm{kJ} / \mathrm{mol}$.

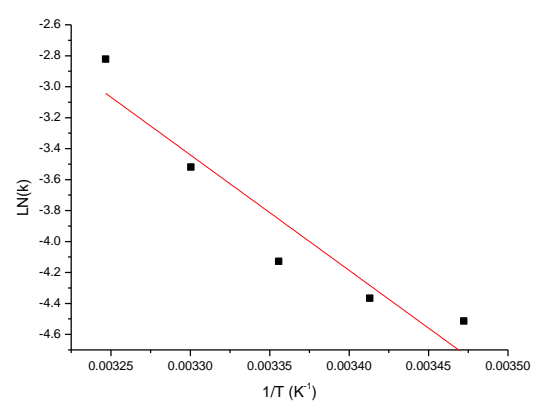

Fig.6. The plot of $\ln \left(1 / \mathrm{t}_{\mathrm{p}}\right)$ vs $1 / \mathrm{T}: \quad$ [Acetone $]_{0}=0.65$

$\mathrm{M}$

$$
\begin{aligned}
& {\left[\mathrm{H}_{2} \mathrm{SO}_{4}\right]_{0}=1.05 \mathrm{M}, \quad\left[\mathrm{CuL}^{2+}\right]_{0}=0.05 \mathrm{M}} \\
& {\left[\mathrm{NaBrO}_{3}\right]_{0}=0.08 \mathrm{M},[\text { Glucose }]_{0}=0.06 \mathrm{M}}
\end{aligned}
$$

The relationship between the potential of the platinum electrode and the potential of the bromide ion electrode is described iconically in the Fig.7.

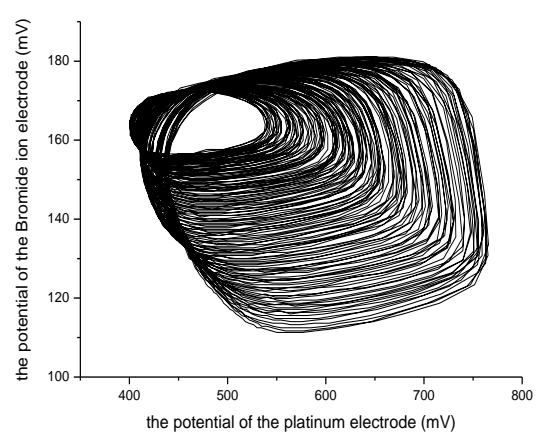

Fig.7. the potential of the platinum electrode vs the potential of the bromide ion electrode for the system at $30^{\circ} \mathrm{C}$ :

$\left[\mathrm{NaBrO}_{3}\right]=0.08 \mathrm{M}, \quad[\text { Acetone }]_{0}=0.65 \mathrm{M}$,

$\left[\mathrm{H}_{2} \mathrm{SO}_{4}\right]_{0}=1.05 \mathrm{M}$

$[\text { Glucose }]_{0}=0.06 \mathrm{M},\left[\mathrm{CuL}^{2+}\right]_{0}=0.05 \mathrm{M}$

In order to investigate whether free radical steps were involved, we tested $\mathrm{H}_{2} \mathrm{O}_{2}$ [18-20]. When the oscillations were held up briefly, the amplitude and oscillations decreased as soon as the concentration of $\mathrm{H}_{2} \mathrm{O}_{2}$ in the oscillation system reached $9.7 \times 10^{-3} \mathrm{M}$. This indicates that there are free radical steps involved in the mechanism of oscillation.

When the concentration of vitamin $\mathrm{C}$ in the oscillation system reached up to $1.0 \times 10^{-2} \mathrm{M}$, the chemical oscillations could be restrained momentarily, similar to the effect of vitamin $\mathrm{C}$ in the $\mathrm{Ce}$ (III) catalyzing B-Z oscillation system[21-22] .This phenomenon makes it clear that $\mathrm{HBrO}_{2}$ is a very important intermediate in the system.

By adding $\mathrm{Ag}^{+}$to the oscillation system, bromate ions concentration decreased due to the formation of $\mathrm{AgBr}$ precipitate, and the potentiometric oscillation of bromide selective electrode could be temporarily suppressed[23]. From this, it can be seen that the concentration of $\mathrm{Br}^{-}$also acts as an on-off switch in the $\mathrm{NaBrO}_{3}$-lactic acid- $\mathrm{H}_{2} \mathrm{SO}_{4}-[\mathrm{Ni} \mathrm{L}]\left(\mathrm{ClO}_{4}\right)_{2}$ oscillation system.

It is not easy to clarity the mechanism of the present oscillation system. From everything stated above, this new oscillation can still happen without glucose. At this time, bromine has a substitution reaction with acetone because there are reactive hydrogens in the acetone, which results in bromide ions . There are a series of redox reactions between bromate in the solution and bromide ions, which render the whole system able to be continuous. This is the reason why oscillation can be found when solely the acetone exists. When acetone and glucose are the double substrates in the system, glucose can have similar reaction with bromine for the reactive hydroxyl radicals in the glycolic chemical reaction. When no additional brominating reagent were supplied, it is necessary to debate on $\mathrm{Br}_{2}$ consumption. Pyruvic acid is thought to be an intermediate. We assume that the brominating reaction may take place on pyruvic acid, the oxidized product of the organic mixed substrate. 
Therefore, the following reactions occur during the oscillation:

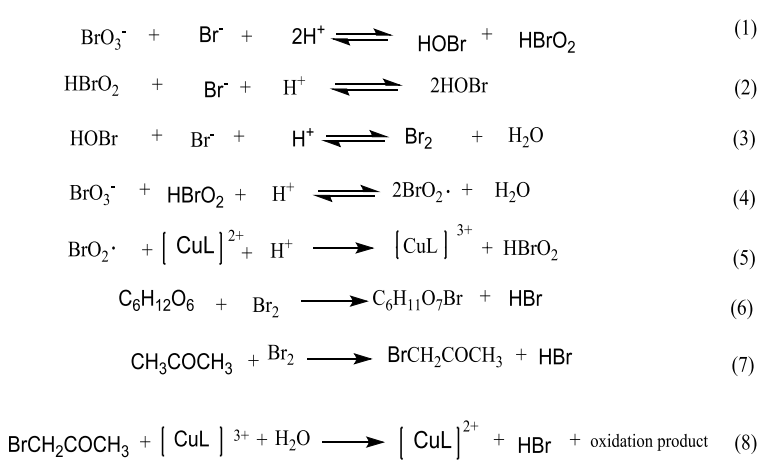

Glucose is the energy source for human being. The analogical research on the oscillatory reaction with glucose being substrate will help man to make clear the complex and significant biochemical mechanism.

\section{Conclusion}

New $\mathrm{Cu}$ ( II )-catalyzed oscillating reaction involved glucose and acetone as the double substrates is proved to be effective. This oscillation can not exist without acetone in the whole system but do without glucose. When the concentration of glucose increase to be $0.04 \mathrm{M}$, the amplitude of oscillation is minimum, when the concentration of glucose increase to be 0.06 , the amplitude of oscillation is maximum, but with the concentration of glucose increasing, the period of oscillation reduce constantly. When it comes to the effect of the concentration of acetone, sodium bromate and tetraazamacrocyclic copper(II) complex to the oscillatory parameters, there are the maximal of concentration respectively . the activation energy was calculated as $90.839 \mathrm{~kJ} / \mathrm{mol}$ and this tentative mechanism is proved to be based on FNK through adding $\mathrm{H}_{2} \mathrm{O}_{2}$, vitamin $\mathrm{C}$ and $\mathrm{Ag}^{+}$to the system respectively.

\section{Acknowledgment}

The authors gratefully acknowledge financial funding of this work by the National Science Foundation of China ( 31160187 ).

\section{References}

[1]M.

Bier,

B.Teusink B.N.Kholodenko,H.V.Westerhoff, Biophys. J. 62 (1996)

[2] J. Wolf, R. Heinrich, Bichem.J. 345 (2000)

[3] Melicherčík M, Treindl L', Chem. Phys. Lett. 196 (1992)

[4] Field RJ, Boyd PM, Phys. Chem. 89 (1985)

[5] Gaspar V, Galambosi P,Phys. Chem. 90 (1986)

[6] Noszticzius Z, Bodiss J,J.Am.Chem.Soc. 101 (1979)

[7] Noszticzius Z, Stirling P, Wittmann M,Phys. Chem. 89 ( 1985)

[8] Pelle K, Wittmann M, Lovrics K, Noszticzius Z, Phys. Chem. 108 (2004)

[9] Wittmann M, Stirling P, Bódiss J, Chem. Phys. Lett. 141 (1987)

[10] El-Boraey HA, El-Gammal OA,Spectrochim. Acta, Part A. 138 (2015)

[11] Bychkov VY, Tyulenin YP, Slinko MM, Korchak VN, Appl. Catal., A. 321 (2007)

[12] Sun H, Lin H, Zhu S, Zhao G, Su X, ChenY, Polyhedron. 18 (1999)

[13] Zhao G, Sun H, Lin H, Zhu S, Su X, Chen Y,Inorg. Biochem. 72 (1998)

[14] Lin H, Zhu S, Kondiano AB, Su X, Kou F, Chen Y, Polyhedron. 17 (1998)

[15] Choi K-Y, Suh I-H, Inorg. Chim. Acta. 299 (2000)

[16] Choi K-Y, Chun K-M, Suh I-H, Polyhedron. 18 (1999)

[17] Choi K-Y, Lee H-H, Suh I-H, Kim J-G, Shin U-S, Inorg. Chim. Acta. 321 (2001)

[18] Tóthová M, Nagy A, Treindl L't, Chem. Phys. Lett. 299 (1999) 
[19] Barros WRP, Reis RM, Rocha RS, Lanza MRV,Electrochim. Acta. 104 (2013)

[20]yothi KP, Yesodharan S, Yesodharan EP, Ultrason. Sonochem. 21(2014)

[21] Tajmir-Riahi HA. J. Inorg,Biochem. 42 (1991)

[22] Gao J, Yang H, Liu X, Ren J, Lu X, Hou J, et al,Talanta. 55(2001)

[23] Treindl L, Hemmingsen T, Ruoff P,Chem. Phys. Lett. 269 (1997) 